\title{
Graduação em Museologia: significados, opções e perspectivas
}

\author{
Lillian Alvares \\ Universidade de Brasília
}

\begin{abstract}
RESUMO: Apresenta o Curso de Bacharelado em Museologia da Universidade de Brasília. Destaca que a primeira tentativa de implantar a graduação data de 1964, seguida por outras duas iniciativas de capacitação na área, em 1988 e em 1991. Somente com o Programa de Reestruturação das Universidades (Reuni), enfim foi concebida a graduação, a partir do consórcio interdisciplinar entre a Faculdade de Ciência da Informação e os Departamentos de Antropologia, de Artes Visuais e de Historia. Dentre as perspectivas que se avizinham ao aprendizado em Museologia o artigo trata das questões centrais dos novos modelos de aprendizagem, a responsabilidade cultural, a identidade nacional, as tecnologias da informação e a convergência entre arquivos, bibliotecas e museus.
\end{abstract}

PALAVRAS-CHAVE: Museologia. Museologia e Interdisciplinaridade. Universidade de Brasília.

ABSTRACT: Describes the implemmentation of the Bachelor Degree in Museology at the University of Brasilia. Reports on its' history, which first, frustrated, initiative was in 1964, and that had two other previous attempts, in 1988 and 1991. However, only with the support of the Programme directed to the restructuring of Universities, led by the Brazilian Ministry of Education (Reuni), it was possible to effectively implemment the course. It constituted a joint and multidisciplinary effort among the following academicinstitutions of the University of Brasilia: Faculty of Information Science; and the Departments of Antropology, Visual Arts and History. The present article also stresses some directives which underline thelearning proposition of the course: cultural responsibility, national identity, full use of information and communication technologies, and the convergence between archives, libraries and museums.

KEYWORDS: Museology, Interdisciplinarity and Museology, University of Brasilia

A instituição do novo curso de bacharelado em Museologia da Universidade de Brasília em 2009 ocorreu na esteira da evolução da compreensão da importância do museu e da Museologia para a sociedade brasileira. Desde 1932, o Brasil tem oferta de graduação em Museologia, mas só nos anos 2000 elevou a soma para mais de uma dezena de cursos em todo o país.

Na Região Centro-Oeste, a capacitação está restrita apenas a duas universidades. Este cenário intensifica a responsabilidade da UnB na formação de museólogos que possam atender a demanda por temas relacionados ao patrimônio cultural, à 
preservação e conservação de bens culturais, à informação e documentação museológica e à teoria e prática museológica. Na busca por excelência, de maneira sistemática ocorre o monitoramento da pesquisa sobre a atividade museal e o acompanhamento das necessidades do mercado de trabalho, a fim de manter o Curso em sintonia com as tendências que se avizinham.

Seu principal objetivo é auxiliar os alunos na identificação das questões centrais na condução de uma profissão rica em conhecimentos, em desafios e, sobretudo, em perspectivas profissionais. Espera-se, enfim, formar museólogos competentes, capazes de reconhecer oportunidades de crescimento da Museologia no Brasil e no Mundo.

\section{Antecedentes}

Há vinte anos, o Departamento de Ciência da Informação e Documentação da Universidade de Brasília apresentou proposta de criação do Curso de Museologia. A iniciativa foi da museóloga Lais Scuotto, diretora do Museu Postal e Telegráfico da Empresa Brasileira de Correios e Telégrafos e do Prof. Antônio Miranda, daquele Departamento.

Na mesma época, a Unesco promoveu mesa redonda internacional, organizada pela International Federation of Library Associations, para apresentar proposta de diretrizes para a harmonização curricular dos cursos de Arquivologia, Biblioteconomia e Museologia no âmbito da Ciência da Informação. Como principal resultado da participação da Universidade de Brasília no evento, está a dissertação de mestrado defendida no Programa de Pós-Graduação em Ciência da Informação, intitulada Tendências para a Harmonização de Programas de Ensino de Arquivologia, Biblioteconomia e Museologia no Brasil: um estudo Delfos. A pesquisa incluiu ampla consulta à profissionais da área, pesquisadores e acadêmicos de todo o Brasil atuantes naquele período, visando à criação de base 
epistemológica e à formulação de proposta de tronco comum de conhecimentos entre as áreas.

A próxima iniciativa viria em 1988, quando o mesmo Departamento de Ciência da Informação apresentou ao MEC o projeto de criação do Curso de Especialização em Museologia, formado por professores de várias cidades brasileiras, principalmente do Rio de Janeiro e de Belo Horizonte. 0 projeto foi aprovado no MEC, mas o curso foi cancelado devido à inflação daquele período que reduziu fatalmente o valor dos recursos.

Na origem da UnB, temos a preciosa colaboração da professora Lygia Martins Costa. A pedido de Darcy Ribeiro, ela montou proposta do Curso Básico para Pessoal Científico de Museus de História e Arte, que previa teste de sensibilidade artística e fluência em inglês e francês. 0 projeto teve aprovação imediata. Lygia ficou três semestres em Brasília, mas a revolução de 64 desmontou a proposta. Ficou a rica experiência da discussão de um currículo eclético, integrador e ainda hoje, inovador.

O atual projeto do curso de graduação em Museologia, inserido na proposta de Reestruturação das Universidades (Reuni), foi concebido pela Faculdade de Ciência da Informação e pelos Departamentos de Antropologia, de Artes Visuais e de Historia, unidades acadêmicas signatárias do Termo de Compromisso entre as Unidades Integrantes do Consórcio de Museologia, datado de 9 de agosto de 2008.

Com a assinatura do Termo de Compromisso, as Unidades integrantes do Consórcio do Curso de Museologia assumem a responsabilidade de colaborar no desenvolvimento das atividades pedagógicas do curso, oferecendo disciplinas previstas na grade curricular como obrigatórias para a formação do aluno, dentro dos seguintes eixos temáticos: Teoria e Prática Museológica; Museologia e 
Informação; Museologia e Patrimônio Cultural; Preservação e Conservação de Bens Culturais.

\section{Opções da Universidade de Brasília: Interdisciplinaridade}

O Curso de Museologia da Universidade de Brasília julga essencial incorporar conhecimentos oriundos das mais diversas áreas na formação do Museólogo. Considera que as intersecções identificadas na Antropologia, nas Artes Visuais, na Ciência da Informação e na História, sobretudo nessas, são responsáveis pela ampliação da visão do profissional, pela multiplicação de oportunidades de pesquisa, pela celeridade na solução de problemas, enfim, pela presença competente nos mais diversos meios de atuação: museus, bibliotecas, arquivos, centros culturais, órgãos de patrimônio histórico, artístico e cultural, produção cultural, atividades relacionadas ao turismo ecológico, educativo e cultural, entre tantos outros.

A interação exigida solicita educadores das mais variadas formações e experiências a fim de debater os problemas que transcendem a especificidade da teoria e prática museológica. Os limites educacionais estendidos ajudam a preparar a próxima geração para superar barreiras, criando profissionais que resultaram de poderosa obra de esforço unificado.

Da Antropologia, são as disciplinas Antropologia da Arte, Cultura e Meio Ambiente, Estudos Afro-brasileiros, Pensamento Antropológico Brasileiro, Sociedades Camponesas, Sociedades Indígenas e Tradições Culturais Brasileiras, em regime de cadeia seletiva, que irão trazer o conhecimento desejado nessa área. Das Artes Visuais são as disciplinas Fundamentos de Linguagem Visual e História da Arte no Brasil, responsáveis por levar ao início da compreensão e da capacidade de expressão artística. Da Ciência da Informação, as metodologias do trato de registros do conhecimento, com as selecionadas Análise da Informação, Controle Bibliográfico, Conservação e Preservação de Documentos e Introdução à 
Biblioteconomia e Ciência da Informação. E a História, com o aporte das disciplinas Cultura Brasileira, História Regional, História Social e Política do Brasil, Introdução ao Estudo da História, essenciais ao perfeito domínio do conjunto de acontecimentos relativos à memória da humanidade.

\section{Eixos Temáticos}

Os conteúdos curriculares obrigatórios de natureza científica tem o total de 169 créditos (2535 horas) e farão parte do Núcleo Básico do Curso de Bacharelado em Museologia. Destes, 8 créditos (120 horas) correspondem aos estágios supervisionados e 8 créditos (120 horas) à elaboração do trabalho de conclusão do curso. Com o propósito de ampliar a flexibilidade e atender interesses e necessidades dos alunos, pelo menos 51 créditos (765 horas) serão compostos por disciplinas optativas. Além desse total estão previstos 24 créditos em Módulo Livre, correspondentes a atividades acadêmicas, científicas, culturais, atividades de extensão e complementares.

O Curso está dividido em 4 eixos temáticos. 0 Eixo 1, intitulado Teoria e Prática Museológica focaliza a formação específica de conteúdos teóricos e práticos voltados para a Museologia, a Teoria Museológica, a Pesquisa Museológica e a Museografia. As disciplinas específicas da Museologia são: Introdução à Museologia, Museologia 1, 2 e 3; Museologia e Comunicação 1, 2, 3 e 4 e Gestão de Museus e Políticas de Acervos Museológicos. O Eixo 2, intitulado Museologia e Informação congrega disciplinas partilhadas pelos cursos de Biblioteconomia e Arquivologia, junto às quais se perfila uma nova disciplina centrada no processamento técnico de acervos realizado no campo da Museologia, intitulada Informação e Documentação Museológica. O Eixo 3, nomeado Museologia e Patrimônio Cultural, objetiva explorar a interdisciplinaridade, com foco na Cultura, Memória e Patrimônio. A disciplina específica da Museologia é Museologia, Patrimônio e Memória. Finalmente, o Eixo 4, intitulado Preservação e Conservação de Bens Culturais é teórico e prático voltado para o campo da preservação e 
segurança de bens Culturais, para o planejamento, a montagem e a gestão de reserva técnica museológica e para os estudos dos procedimentos de manuseio, transporte e exibição. As disciplinas específicas da Museologia são Museologia e Preservação 1 e 2.

Além dos conteúdos curriculares abordados acima, 14 créditos (210 horas) de atividades de caráter acadêmico, científico ou cultural e de livre escolha dos estudantes poderão incluir atividades de ensino, pesquisa e extensão de acordo com critérios estabelecidos pelo Colegiado da Faculdade de Ciência da Informação (FCI). A solicitação de reconhecimento dos créditos será analisada pela Coordenação de Graduação e submetida à aprovação pelo Colegiado da FCI. As atividades de extensão deverão atender aos critérios definidos na Resolução do CEPE 87/2006 e poderão integralizar, no máximo, 10 créditos. As atividades de pesquisa também poderão integralizar, no máximo, 10 créditos. As atividades que não se enquadrarem em quaisquer dessas modalidades poderão integralizar, no máximo 4 créditos.

\section{Laboratórios}

Para pleno funcionamento do Curso de Museologia é essencial o suporte de laboratórios. No momento, eles estão sendo estruturados, de acordo com o seguinte planejamento:

- Laboratório de Museologia e Exposição Curricular (Lamec): tem como objetivo entender como são organizadas as exposições, considerando os espaços nos museus, a relação entre o visitante e o que está exposto, as metodologias de interpretação do real, os códigos de percepção visual, as estratégias de comunicação e a comunicação com grupos minoritários. Dentre os elementos de projeto de uma exposição, o Laboratório poderá aprofundar na prática das questões da linguagem e expressão nas exposições museológicas, no conteúdo e forma, na tipologia de exposição, nas especificidades em relação à duração da 
exposição, nos elementos expográficos, tais como suportes, cores, som, iluminação, texturas, imagens, textos, cenários e outros. Aqui serão realizados projetos de ações museais diversas, e de ação cultural e exposições para diferentes públicos, incluindo produção, montagem e programação de curadoria expográfica. Conta com uma oficina específica de Educação Patrimonial.

- Laboratório de Museografia e Reserva Técnica (Lart): tem a função de proporcionar ao aluno a prática da guarda do acervo não exposto, observando precauções especiais quanto à localização, proteção contra roubo, catástrofes e condições ambientais apropriadas. A coleção na Reserva Técnica precisa estar acondicionada em local apropriado e, quando necessário, na parte externa são anotadas as principais características da peça, como: datação, origem e descrição física. Pela Reserva Técnica, que assegura a movimentação organizada e segura de materiais, os museus renovam constantemente seu acervo e o visitante percebe as intervenções periódicas na instituição. A missão de difusão cultural, educação patrimonial e desenvolvimento social e da cidadania estão intimamente relacionados a esse Laboratório. A Reserva Técnica é tão importante quanto o próprio museu. É o lugar adequado tecnicamente para dar suporte às atividades museológicas, por isso é de vital importância sua prática. Geralmente, a Reserva possui inúmeras peças, acervos completos, coleções de estudo, incluindo as respectivas estruturas expográficas, que aguardam catalogação, cadastramento, inventário, restauro, outras intervenções ou aguardam para uma exposição. A Reserva Técnica é o local para a realização da manutenção do que está exposto, como também do que será mostrado nas exposições temáticas. Conta com uma oficina específica de Documentação.

- Laboratório de Prevenção, Conservação e Restauração (Lacon): tem como objetivo promover o desenvolvimento da investigação científica nas áreas da conservação e restauro. Serão realizadas atividades de ensino e pesquisa no campo da conservação, conservação preventiva e restauração de peças típicas 
de acervos museológicos. As atividades têm como referencial a manutenção da integridade e da autenticidade dos elementos constitutivos do objeto museal no momento do projeto e da intervenção técnica. Para que tais atividades sejam mais bem executadas, serão estabelecidos acordos de cooperação com laboratórios de conservação no país. Conta com a Oficina de Conservação e Restauração de Obras sobre Papel.

- Laboratório de Multimídia e Espaços Virtuais (Lev): desenvolve tecnologias e metodologias para promover a difusão de exposições, a partir da criação de ambientes virtuais envolvendo o acervo de museus. 0 ambiente virtual dá a oportunidade de apresentar exposições de formas alternativas no ambiente real de um museu. 0 Laboratório tem como referencial seguir a arquitetura real de museus, dado que estudos afirmam que dessa maneira a exposição virtual tem impacto sobre seu público-alvo. Serão usadas imagens reais, com base em fotografias, plantas de arquitetura e coleções para a criação dos elementos do ambiente virtual, a fim de aproximar o quanto possível o ambiente virtual do ambiente real. 0 trabalho de pesquisa do Laboratório envolve também, o desenvolvimento de outras aplicações em ambientes virtuais, tais como a comunicação e seu público em ambiente virtual, o desenvolvimento de metodologias de ensino-aprendizagem, coleta de dados, análises e avaliações, com foco na percepção do público alvo no potencial de aprendizagem inserida nas exposições em ambientes virtuais.

\section{Perspectivas na Capacitação: Lifelong Learning e Novos Modelos de}

\section{Aprendizagem}

0 aprendizado ao longo da vida ou lifelong learning é um conceito amplo, que pode relacionar-se à ideia de democracia a todos os cidadãos, independentemente da condição social, levando à igualdade de oportunidades. Nesse contexto, considera a oferta de ensino em universidades corporativas, associações de classe, programas para educação de adultos, entre outros. Pode também, e esse aspecto interessa ao futuro do Curso de Museologia, ser compreendida em termos humanísticos, 
estando relacionado às questões de capacitação: aumentar a autonomia pessoal por meio da aquisição de conhecimentos, dar suporte ao desenvolvimento de competências específicas e às habilidades sociais.

Esse conceito de aprendizagem desempenha um papel importante na construção da Museologia contemporânea. Inúmeros estudos apontam que os processos de aprendizagem envolvem dimensões cognitivas, emocionais e sociais bem como diferentes níveis de engajamento e reflexão (Illeris, 2002). Esse ponto de vista construtivista considera que os alunos constroem seu conhecimento de forma independente e personalizada, de acordo com fatores socialmente e culturalmente incorporados ao estilo individual de aprendizagem.

Como consequência dessa percepção, importa considerar que os ambientes educacionais, que tem como objetivo principal estimular processos de aprendizagem, forneçam aos alunos acesso ao conhecimento por muitos caminhos diferentes. Assim, novos modelos educacionais emergem da constatação de que a aprendizagem para jovens e adultos deve ser de forma diferente daquela para crianças e adolescentes. Para Knowles (1990), os adultos precisam saber por que têm que aprender algo, precisam aprender experimentando, encaram a aprendizagem como a resolução de problemas e aprendem melhor quando os conteúdos têm utilidade imediata.

Destacam-se nessa perspectiva, a Aprendizagem Experiencial e a Aprendizagem Informal - Situada e Incidental. Para Antonello (2007), os modelos de Aprendizado Experiencial baseiam-se, principalmente, nos trabalhos de Dewey, Lewin e Piaget, sendo o conceito mais importante em seu estudo, a noção de experiência. 0 autor define Aprendizagem Experiencial como uma contínua reorganização e reconstrução da experiência, que ocorre todo o tempo e em todas as situações em que as pessoas agem e interagem, refletem e pensam. 
A aprendizagem é apresentada pelo autor como um processo por meio do qual o conhecimento é criado pela transformação da experiência, a partir de seis suposições: (i) aprendizagem é um processo, não um resultado; (ii) deriva da experiência; (iii) exige que um indivíduo solucione demandas dialeticamente opostas; (iv) é sistêmico e integrativo; (v) requer interação entre a pessoa e o ambiente; (vi) resulta em criação de conhecimento.

Já na perspectiva da Aprendizagem Informal, o aprendizado ocorre obrigatoriamente fora do ambiente acadêmico, podendo ainda ser dividido em Aprendizagem Informal Incidental (AII) e Aprendizagem Informal Situada (AIS). No primeiro caso, AII, a aprendizagem é definida como falta de consciência do próprio processo de aprendizagem, ocorrendo por meio da observação, repetição, interação social e resolução de problemas. Na AIS, a aprendizagem ocorre a partir da imersão do sujeito na cultura e ambiente organizacionais, a partir da inserção do sujeito no ambiente da ação e da produção (VIGGIANO, 2007). Ao Curso de Museologia, cabe refletir formas complementares de apoio ao aprendizado tradicional.

\section{Responsabilidade Cultural}

O conceito de capital cultural de Pierre Bourdieu (1930-2002) é bem conhecido. Sinteticamente, é a tradução do capital econômico em hierarquias culturais. Poder e privilégios se traduzem em distinções mais refinadas, reservadas às classes sociais com maior poder econômico. Ao que ele chama também de capital informacional, está reservado àqueles com acesso ao conhecimento.

Essa condição enfatiza que a origem social dos alunos resulta em desigualdades escolares. Portanto, o capital cultural é relevante no processo de formação e, mais do que isso, é determinante no sucesso ou no fracasso de uma trajetória de aprendizagem. 
Considerando que Bourdieu distingue três estados do capital cultural, um deles está reservado à responsabilidade dos educadores: aquela que afirma que o capital cultural não é apenas acumulado por indivíduos, mas institucionalizado pelo Estado e pressupõe sua acumulação cultural em academias, escolas, universidades, museus, arquivos e bibliotecas. Nesse caso, o que o caracteriza não é tanto que ele pode ser acumulado, mas que é fluido, que pode ser convertido em outras formas de capital, tais como competências laborais ou capital econômico. E é esse o ponto central do que chamamos de Responsabilidade Cultural, auxiliar os alunos com baixo capital cultural à experiência não disponível em família.

A propósito, o primeiro estado caracteriza-se como um bem incorporado, acumulada e cultivada por indivíduos de uma mesma família, às vezes por gerações, cuja situação de classe determina a quantidade de capital cultural adquirida e o segundo estado são os próprios objetos e informações, que podem ser transmitidas para consumo por outros indivíduos capazes de compreender os significados inscritos.

\section{Identidade Nacional}

Diferente de muitos países, em geral, os brasileiros não exultam sua nacionalidade. Vale deixar a frase dita pelo historiador inglês Arnold J. Toynbee depois de viajar por todo o continente sul-americano em 1955: "enfim, cheguei a um país sem heróis". A referência era, na verdade, um elogio, já que o entusiasmo dos nossos vizinhos continentais com seus momentos militares históricos chegou a causar cansaço ao viajante. Ao pronunciar essa frase, ele reflete a acolhida que teve ao chegar ao Brasil: a indiferença de nossa cultura em relação a nossa história.

Os museus e, por conseguinte, os museólogos tem o notável dever de representar a identidade nacional. Os debates sobre o assunto realçam novos desafios para a profissão em torno da questão, dentre eles, a promoção da integração nacional dentro da pluralidade e diversidade de identidades regionais. Soma-se a isso, as 
agendas social e política do século 21, que tratam do multiculturalismo, de movimentos de mulheres, de movimentos para o reconhecimento de homossexuais, de respeito ao meio ambiente, dentre outros, o que avulta a tarefa dos museus em narrar a diversidade de nação.

Aos museólogos, cabe abraçar as dinâmicas da mudança social, acentuar a voz do nacionalismo histórico e contemporâneo, remover homogeneidade e pontos de vista único, rejeitar a exclusão, incentivar a complexidade e o pluralismo, tornando-o local para o diálogo da identidade nacional e da inclusão social. Aos professores de museologia, cabe a formação obrigatória também do cidadão.

\section{Tecnologias da Informação e Convergência entre Arquivos, Bibliotecas e Museus}

Paul Otlet (1868-1944) preocupava-se com a representação e organização da informação. Acreditava que tal empreendimento poderia ajudar a estabelecer a paz mundial, pois a oferta de um sistema de armazenamento de dados em vários campos da ciência, certamente, promoveria acesso universal ao conhecimento e elevaria a sociedade a um novo patamar de civilidade.

Naquela época, não foi possível concretizar o sonho em toda a sua plenitude, e, desde então, o volume de informação só aumentou. Nesse meio-tempo, e, principalmente nas últimas duas décadas, a revolução tecnológica na comunicação e na informação impactaram de forma permanente a maneira como organizar o conhecimento, deixando pequena distância ao sonho de Otlet.

A inovação tecnológica forneceu novos instrumentos para o trabalho tradicional dos museólogos e abriu novas possibilidades de atuação. No entanto, a capacidade de usar essas ferramentas requer novos conhecimentos, nova postura diante das possibilidades que se aproximam, definições políticas, decisão de investimento, 
normalizações e padronizações, dentre tantas mudanças que chegam na propulsão das novas condições.

Apenas para identificar uma das possibilidades, a convergência tecnológica possibilita de forma fascinante a colaboração entre Arquivos, Bibliotecas e Museus, que até o momento nunca estiveram em condições de se concretizar completamente. É possível responder, de uma nova maneira, às seguintes questões clássicas da interação entre essas instituições: (i) quais são as necessidades de informação em arquivos, bibliotecas e museus? (ii) quais são os papéis e responsabilidades dos profissionais da informação em arquivos, bibliotecas e museus na era da informação? (iii) que tipos de capacitação prepara melhor os profissionais da informação para atender a necessidades dos arquivos, bibliotecas e museus e seus usuários na era da informação?

Em resposta à essa nova era, a pesquisa progrediu, resultando em inúmeros trabalhos sobre a convergência das três áreas, cujo título mais emblemático é Arquivos, Bibliotecas, Museus e a Magia do Conhecimento Onipresente, escrito por Thomas Kirchhoff, Werner Schweibenz, e Jörn Sieglerschmidt. Nesse trabalho em particular, os autores exploram a ideia de que na internet, ninguém sabe se está lidando com arquivo, biblioteca ou museu, pois as pessoas querem a informação e muitas vezes não estão interessadas em saber de onde ela vem, desde que venha de uma organização cujo presença virtual seja o mais transparente possível.

Naturalmente, as pesquisas têm muito em comum, com temas que transcendem os limites funcionais de arquivos, bibliotecas e museus e desafiam a simples classificação das instituições. Alguns trabalhos observam que arquivos, bibliotecas e museus têm que arriscar-se na web sob o risco de perder importante parcela de seu público. Outros afirmam que os profissionais devem tirar proveito de novas tecnologias para alargar o acesso à informação para novos usuários e novos usos. 
Incentivam o crescimento de comunidades em torno de experiências tanto no uso da tecnologia como no compartilhamento de boas práticas.

A Faculdade de Ciência da Informação tem se dedicado a estudar a integração curricular dos cursos de graduação em Arquivologia, Biblioteconomia e Museologia. Para isso, criou a Comissão de Integração Curricular cujos resultados estão no documento Identificação do Eixo Integrador: tronco comum de disciplinas da Faculdade de Ciência da Informação. Os resultados do esforço são a organização do conhecimento em quatro grupos principais. 0 primeiro, intitulado Construção do Saber, constitui-se das disciplinas Organização do Trabalho Intelectual, Introdução à Pesquisa em Ciência da Informação e Monografia em Ciência da Informação. 0 segundo, Ciência da Informação, inclui as disciplinas Introdução à Ciência da Informação, Fundamentos da Organização da Informação, Patrimônio Cultural e Preservação e Conservação de Documentos. 0 terceiro, Instituições e Usuários, compreende as disciplinas Estudo de Públicos e Usuários e Planejamento de Unidades Culturais e de Informação. 0 quarto e último grupo, Tecnologia, inclui a disciplina Tecnologias para Ciência da Informação. A introdução dessa visão, no entanto, ainda não está terminada. Espera-se que esse passo seja dado em breve.

\section{Conclusão}

Em 2009, a Universidade de Brasília deu início ao Curso de Museologia, com a participação direta de quatro unidades acadêmicas: Antropologia, Artes, Ciência da Informação e História. Com essa opção, a interdisciplinaridade necessária foi garantida, abrindo espaço para interações optativas com outras áreas do conhecimento. Os laboratórios estão em fase de estruturação e são projetados para atender a várias disciplinas distribuídas em quatro eixos temáticos: Teoria e Prática Museológica; Museologia e Informação; Museologia e Patrimônio Cultural e Preservação e Conservação de Bens Culturais. 
A preocupação em manter o nível de excelência do Curso se reflete nas perspectivas que cercam o futuro dessa graduação, no que se refere aos novos modelos de aprendizagem, às preocupações com a questão da responsabilidade cultural, a pressão pela intensificação da identidade nacional e a disponibilidade das novas tecnologias de informação que resultam também na convergência entre Arquivos, Bibliotecas e Museus. Nesse sentido, a Faculdade de Ciência da Informação estudou e apresentou a proposta da Comissão de Integração Curricular para identificar o eixo integrador dos Cursos de graduação em Arquivologia, Biblioteconomia e Museologia.

\section{REFERÊNCIAS}

ANTONELLO, C. S. Aprendizagem na ação revisitada e seu papel no desenvolvimento de competências. Aletheia, n. 26, p. 146-167, 2007.

BOURDIEU, P. Escritos de educação. Petrópolis: Vozes, 1998.

ILLERIS, K. The three dimensions of learning: contemporary learning theory in the tension field between the cognitive, the emotional and the social. In: Hooper-Greenhill, E. (org). The educational role of the museum. London: Routledge, 2002.

KIRCHHOFF, T.; SCHWEIBENZ, W.; SIEGLERSCHMIDT, J. Archives, libraries, museums and the spell of ubiquitous knowledge. Archival Science, v. 8, 2009.

KNOWLES, M. S. The adult learner. Washington: Gulf Publishing, 1990.

VIGGIANO, A. R. O ciberespaço enquanto ambiente informal de aquisição de competências. 2007. 217 f. Dissertação (Mestrado em Educação Tecnológica) - Coordenação do Mestrado em Educação Tecnológica, Centro Federal de Educação Tecnológica de Minas Gerais (CEFET-MG), Belo Horizonte, 2007. 